\title{
OS INTERMETATARSEUM AND A POSSIBLE RELATIONSHIP TO HALLUX VALGUS*
}

\author{
Robert S. Henderson, Edmonton, Alberta, Canada
}

From the Orthopaedic Departments of University Hospital and Misericordia Hospital, Edmonton

The accessory bones of the foot have fascinated anatomists for five centuries. Andreas Vesalius in 1568 (published in 1725) was the first to draw attention to an accessory ossicle situated at the base of the fifth metatarsal bone, and much has been written subsequently about two distinct groups of accessory bones. In the first are those which are contained within the fibres of tendons and are true sesamoid bones. In the second ossicles are found lying in the tarsus and the forefoot which are of embryological interest only and which do not as a rule contribute to the mechanics of the foot (O'Rahilly 1953).

The os intermetatarseum, a rare accessory bone of the forefoot, is occasionally found lying between the bases of the first and second metatarsal bones. It was first described by Gruber (1856). It was also noted by several anatomists of the nineteenth century in their dissections of anatomical specimens. Pfitzner (1896) gave the first detailed account of the ossicle (Fig. 1) and, after his work was published, it was rediscovered at least three times in the early part of this century. Shands (1931), in a study of over 400 radiographs of the foot, found

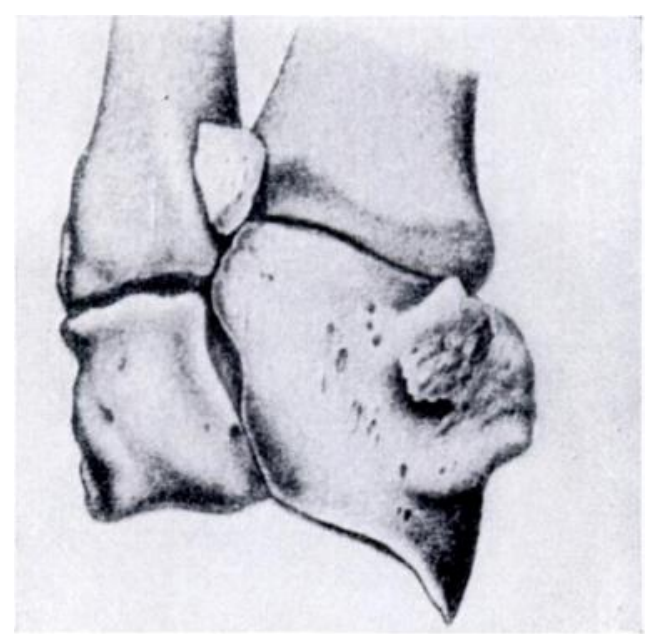

FIG. 1

Os intermetatarseum (after Pfitzner). the ossicle in 1.24 per cent of cases. Dwight (1907) had quoted a considerably higher figure.

It has been recognised that there are several different types and shapes of the os intermetatarseum (Fig. 2). It is most commonly seen in radiographs as a separate ossicle,
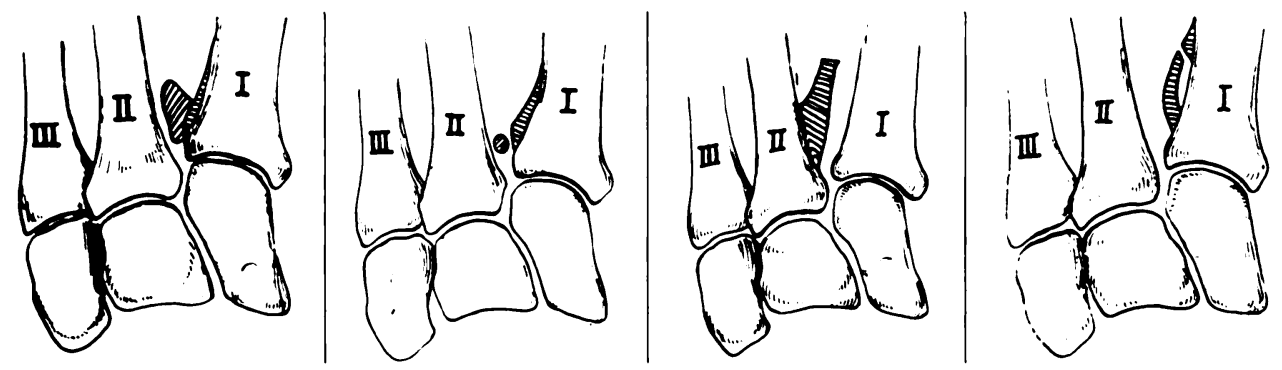

FIG. 2

Various forms of os intermetatarseum (after Schinz).

but it may arise as a spur from the base of the first or second metatarsal bone or from the medial cuneiform bone. It sometimes articulates with the base of the first or second metatarsal bone.

${ }^{*}$ Based on a paper presented to the Canadian Orthopaedic Association at Waskesiu, Saskatchewan. 
There has been much speculation as to its origin. One of the most popular theories has been that it represents a missing metatarsal bone-in other words it is a form of polydactylism. Wood Jones (1949) believed strongly that this theory could be dismissed. Friedl (1924) described it as a sesamoid bone of the first dorsal interosseous muscle from a calcification of the accessory tendon of the dorsal interosseous muscle. Schwalbe (1917) attempted to explain its presence as an outcome of the transformation of the anthropoid "grip foot" to the human "stand foot." As the first cuneiform bone, carrying the great toe, is rotated along with it, its dorsi-fibular part becomes moulded into a process which acquires the shape of a typical os intermetatarseum.

\section{CASE REPORTS}

Case 1-My interest was first aroused when I saw a nineteen-year-old student with a gross degree of bilateral hallux valgus. Radiograph of both feet (Fig. 3) showed spurs arising dorso-medially from the bases of the second metatarsal bones, the apices of which were directed towards the bases of the proximal phalanges of the great toes. As they appeared to be occupying space between the metatarsal shafts and thereby increasing the varus deformity of the first metatarsal bones I decided to resect the

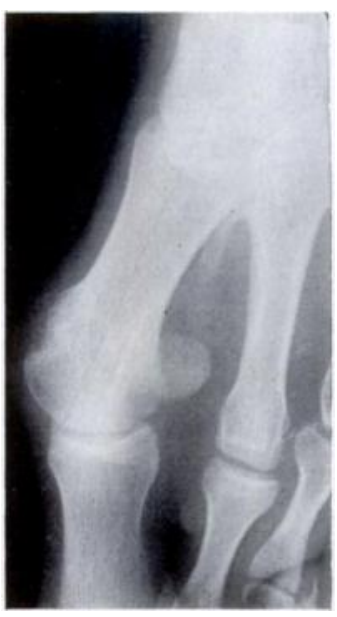

FIG. 3

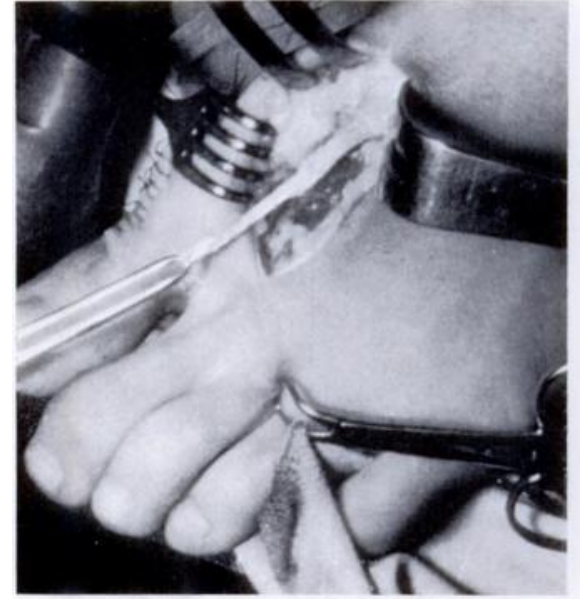

Fig. 4

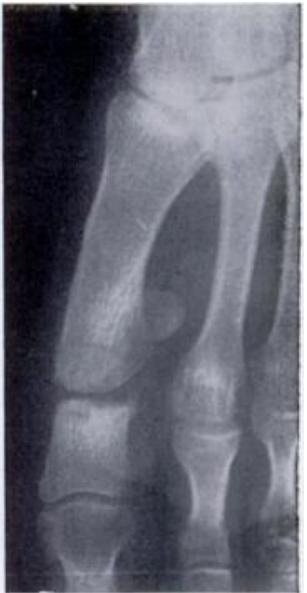

FiG. 5

Case 1. Figure 3-The left foot before operation. Os intermetatarseum and marked hallux valgus. The right foot was similar. Figure 4-The os intermetatarseum and a tendon running from it to the base of the proximal phalanx. Figure 5-Radiograph after operation.

spurs through proximal incisions and in addition to carry out Keller's operation on each side. To my surprise, at operation I found a tendinous structure extending from each spur to the base of the proximal phalanx of the great toe, to which it was attached on the dorso-lateral aspect (Fig. 4). The spur and the tendinous band were resected on each side and histological examination showed typical tendon tissue in each band. An unusually good result was obtained from this combined procedure and radiographs taken three months later showed a degree of correction of the varus deformity of the first metatarsal bone not often seen after most operations for hallux valgus without osteotomy of the first metatarsal bone (Fig. 5).

Case 2-A few months later the boy's sister presented with a marked and painful hallux valgus on the left side and a less marked deformity on the right side. Radiographs showed bilateral intermetatarsal spurs (Fig. 6). Her left foot was operated on in the same way as her brother's feet and the findings were identical. She had an equally satisfactory result.

About a year later this patient returned with pain in her right foot. On this occasion a single incision was made, extending from the base of the second metatarsal bone to the middle of the proximal phalanx of the great toe. The spur was easily exposed and was found to articulate, at what was clearly a synovial joint, with the medial side of the base of the second metatarsal bone (Fig. 7). It was found 


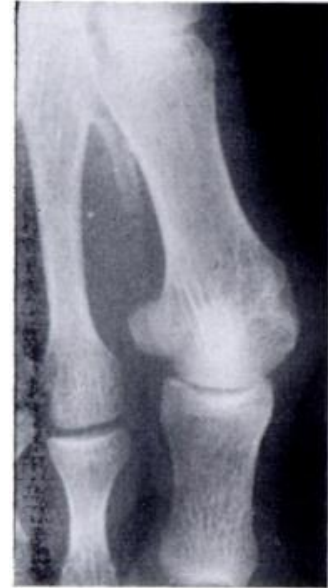

FIG. 6

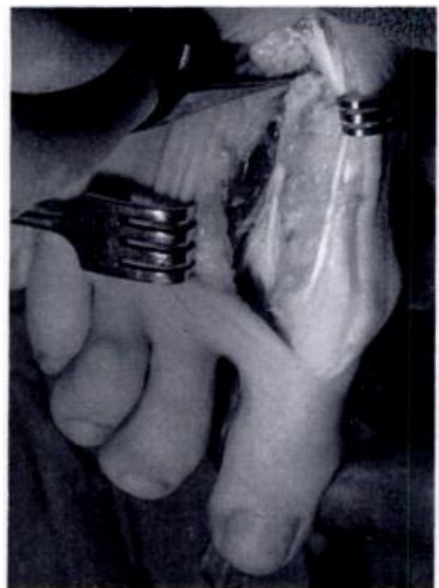

FIG. 7

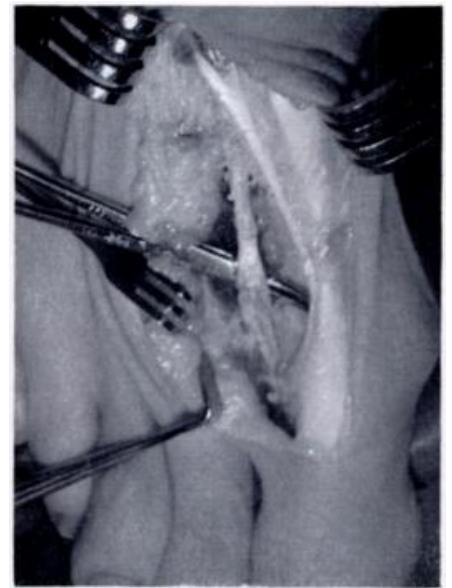

FIG. 8

Case 2. Figure 6-Radiograph of right foot before operation, showing os intermetatarseum. The left foot was similar. Figure 7-Os intermetatarseum with the attached tendon shown articulating with the base of the second metatarsal bone. Figure 8-The attachment of the tendon, arising from the os intermetatarseum, to the lateral side of the base of the proximal phalanx of the great toe.

to lie deep to the extensor hallucis brevis tendon and a tendinous structure was found arising from its tip, as in her brother's feet. This was followed through the belly of the first dorsal interosseous muscle to the proximal phalanx of the great toe where it was found to be attached to the lateral aspect (Fig. 8). The spur and tendon were resected and Keller's operation was performed.

Case 3-To add to the family picture, another brother was seen with bilateral spurs and hallux valgus, but these caused only minor symptoms. In both feet the spurs and the tendons could easily be palpated on the dorsum of the foot and were also visible on the radiographs. The symptoms in this patient were not bad enough to warrant operation.

The mother and father and one other member of the family were examined and were found to have normal feet.

Case 4-A woman of forty-six presented with bilateral hallux valgus and multiple hammer toe deformities. On the left side a small os intermetatarseum of the spur type attached to the base of the first metatarsal bone was seen on the radiographs (Fig. 9). On the right side there was a very small, similarly shaped spur and this was the side of the greater degree of hallux valgus. Both feet were operated upon. On the left side the os intermetatarseum was resected and afterwards the degrees of metatarsus primus varus and hallux valgus were greatly reduced. No tendinous attachments to the spurs were found in either foot.

\section{DISCUSSION}

A careful examination has been made of all radiographs of feet taken in the University of Alberta Hospital, Edmonton, over a six months

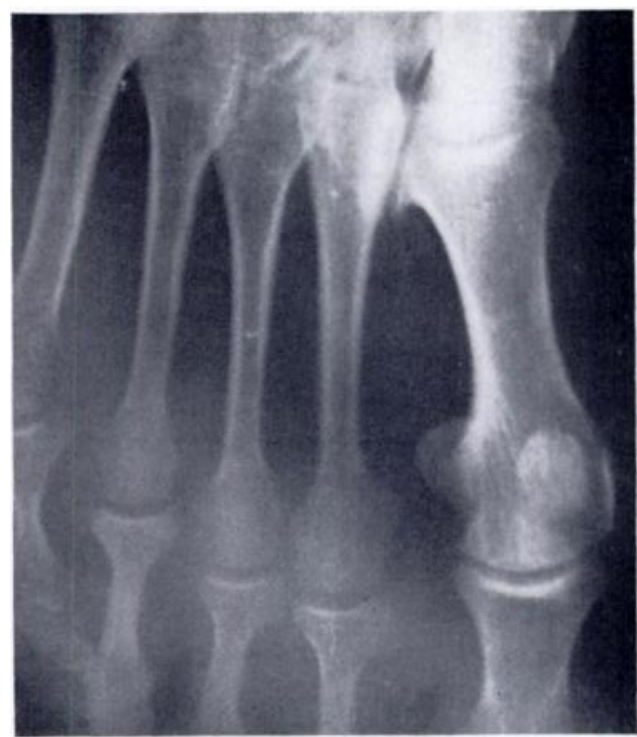

Fig. 9

Case 4-The foot of a woman with an os intermetatarseum acting as a wedge. period. In 300 films taken in that time, only four examples of os intermetatarseum were seen. One of these was associated with a mild but symptomless degree of hallux valgus (Fig. 10). In the other three, one of which was a boy of ten, no deformity was present.

I have been unable to discover in the English literature any reference to an intermetatarsal 
spur with the tendinous attachment that has been described. Waters (1958) described a family with similarly situated and similarly shaped intermetatarsal spurs associated with bilateral

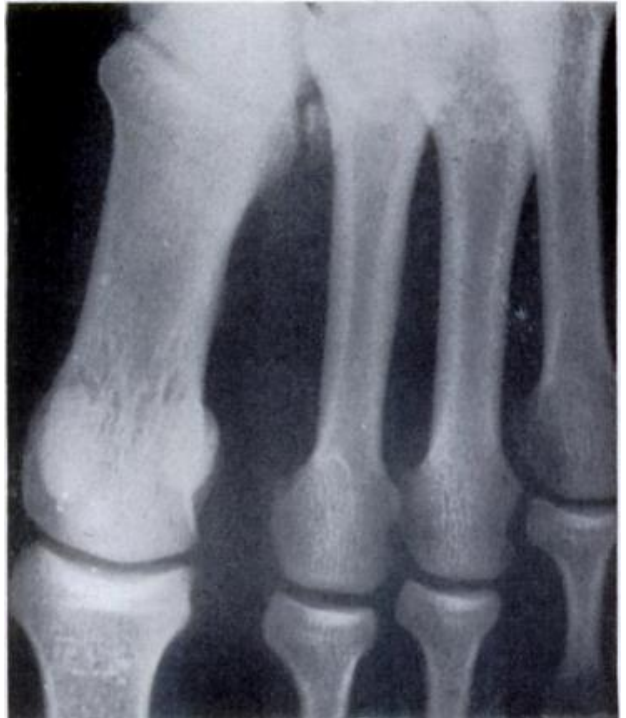

FIG. 10

An os intermetatarseum with mild hallux valgus. hallux valgus. Though he resected the spurs in one patient he did not record the presence of tendinous attachments.

Bearing in mind Wood Jones's observation that in the foot the extensor hallucis brevis is undoubtedly the homologue of the extensor pollicis longus in the fore-limb, I felt at first that this spur and tendon might represent an anomalous extensor hallucis brevis. However, the discovery of a normal extensor hallucis brevis in the later operation (Case 2) discounted this theory. I made a special study of extensor hallucis brevis in all cases of hallux valgus coming to operation at that time and was surprised to find considerable variation in its size and strength. I felt convinced that at times it might play a part in the mechanical production of hallux valgus.

In considering Friedl's suggestion that a spur-like os intermetatarseum may be related to the first dorsal interosseous muscle, I wondered if the tendon attached to the spur could be the accessory tendon of the first dorsal interosseous muscle which he described. However, dorsal interossei in the foot abduct from the mid-line of the second toe and the attachment of the tendon to the proximal phalanx of the great toe is therefore not anatomically acceptable.

Manter (1945) discussed variations in the interosseous muscles of the foot, basing his findings on a study of post-mortem specimens. He agreed with Leboucq (1895) who noted the presence in some instances of a fibrous band extending from the plantar surface of the first dorsal interosseous to the proximal phalanx of the hallux. He felt that this had the regular location and attachments of a typical plantar interosseous muscle and could well represent a remnant of a lost first plantar interosseous muscle. However, neither Manter nor Leboucq reported finding actual muscle or tendon occupying this position.

It is possible, however, that the spurs and tendons which I have described represent a lost first plantar interosseous muscle, which contributes in these cases to the formation of hallux valgus. It seems probable that this anomaly is extremely rare.

\section{SUMMARY AND CONCLUSIONS}

1. A group of cases is presented in which the os intermetatarseum took the form of an intermetatarsal spur, from which (in members of one family) there arose a tendon-like structure whose distal attachment was to the lateral aspect of the proximal phalanx of the great toe. The suggestion is made that this may represent a lost first plantar interosseous muscle.

2. Another effect of the presence of an os intermetatarseum is the production of metatarsus primus varus by its action as a wedge which spreads apart the bases of the two metatarsal bones. A very small wedge may at times produce considerable deviation (Case 4), and resection of the os can result in satisfactory correction.

3. It is also felt that over-development of extensor hallucis brevis may at times contribute to the formation of hallux valgus. 
I should like to express my thanks to the Photographic Departments of the University of Alberta and the Misericordia Hospitals, Edmonton, Alberta, for their great help, and to Mrs B. Rhind for her drawings.

\section{REFERENCES}

Dwight, T. (1907): Variations of Bones of the Hands and Feet. A Clinical Atlas. Philadelphia: J. B. Lippincott Company.

Friedl, E. (1924): Das Os intermetatarseum und die Epiphysenbildung am Processus trochlearis calcanei. Deutsche Zeitschrift für Chirurgie, 188, 150.

Gruber, G. B. (1856): Human and Comparative Anatomy, 111.

Jones, F. Wood (1949): Structure and Function As Seen in the Foot. Second edition. London: Baillière, Tindall and Cox.

LeboucQ, H. (1895): Les Muscles Adductous ou Pouce et on Gros Orteil. Archives de Biologie, 13, 41.

MANTER, J. T. (1945): Variations of the Interosseous Muscles of the Human Foot. Anatomical Record, 93, 117.

O'Rahilly, R. (1953): A Survey of Carpal and Tarsal Anomalies. Journal of Bone and Joint Surgery, 35-A, 626.

Pfitzner, W. (1896): Beiträge zur Kenntniss des menschlichen Extremitätenskelets. VII. Die Variationen im Aufbau des Fussskelets. Jena. [Cutting.]

Schinz, H. R. (1951): Roentgen-Diagnostics. First American edition, p. 124. Edited by J. T. Case. New York: Grune \& Stratton.

SChWALBE, E. (1917): Anthropology and Morphology. Band XX.

Shands, A. R. (1931): Accessory Bones of the Foot. Southern Medicine and Surgery, 93, 326.

Vesalius, A. (1725): Opera ommia anatomica et chirurgica, p. 120. Edited by H. Boerhaave. Lugd. Bat.: J. du Vivie et J. et $\mathbf{H}$. Verbeek.

Waters, L. (1958): Os Intermetatarseum. Journal of the American Paediatric Association, June. 